Peer-Reviewed Article
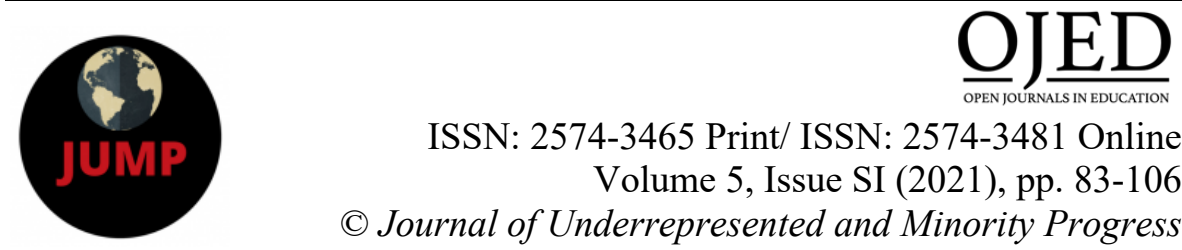

ISSN: 2574-3465 Print/ ISSN: 2574-3481 Online

Volume 5, Issue SI (2021), pp. 83-106

(C) Journal of Underrepresented and Minority Progress

http://ojed.org/jump

\title{
Riding Out the Immigration Storm: Higher Education Responses and Support Provided to International Students in the U.S. During the COVID-19 Pandemic
}

\author{
Masha Krsmanovic, Ph.D. \\ University of Southern Mississippi, USA
}

\begin{abstract}
Government restrictions imposed during the pandemic affected both international students planning to attend U.S. higher education institutions and those currently enrolled. Reviewing the websites of 160 colleges and universities enrolling the highest numbers of international students, this study investigated if and how these institutions supported their international students during the global crisis. The results, obtained through document analysis, revealed that the majority of websites or $74 \%$ provided such guidance, while the remaining $26 \%$ did not. Only $10 \%$ of the institutions issued official statements to and in support of their international students during the pandemic. Based on the findings, the article proposes recommendations for all colleges and universities that are yet to respond to the international members of their academic communities.
\end{abstract}

Keywords: international students, immigration, student support 


\section{INTRODUCTION/BACKGROUND}

COVID-19 disrupted the educational experiences of all students around the world primarily by preventing them from taking face-to-face classes and constraining them to remote instruction. Given the holistic structure of U.S. campuses, reflected through miscellaneous student services, curricular and co-curricular programs, clubs, organizations, and other involvement opportunities, college students in the U.S. were also deprived of social and academic engagement structures critical to their success. Furthermore, the effects of COVID-19 on students' educational experiences remain disproportional, with some groups being negatively impacted more severely than others. These more severely affected groups include economically disadvantaged students, as well as students or caregivers with limited access to health services or those at increased risk of contracting the virus. Among students who have experienced unique challenges during the pandemic are also international students whose academic progress and educational opportunities have been hindered by the immigration measures imposed by the U.S. government as a response to the pandemic.

According to the Institute of International Education (IIE), in 201819 more than one million international students decided to enroll in U.S. higher education institutions (IIE, 2019). The largest share of international students $(39 \%)$ were enrolled in undergraduate programs, 34\% sought graduate education, 20\% were in Optional Practical Training (OPT), and 6\% were non-degree seekers. Unsurprisingly, STEM remained the most desirable field for international students with $21 \%$ enrolled in engineering and $16 \%$ in math and computer science combined. The top five sending countries in 2018-2019 were China, India, South Korea, Saudi Arabia, and Canada.

International students bring numerous benefits to their educational institutions and host societies, including economic, cultural, and academic. According to the Association of International Educators (NAFSA), in 20182019 international students studying in U.S. colleges and universities contributed $\$ 41$ billion and 458,290 jobs to the U.S. economy (NAFSA, 2019). These data are not surprising considering that $62 \%$ of these students supported their education from international funding resources (e.g., personal and family funds, foreign governments and universities or private sponsors) (IIE, 2019).

In addition to the frequently cited financial contributions, international students support U.S. academic communities in many other, not easily measurable ways, such as fostering cultural competence, promoting international relations, and increasing the international prominence of U.S. educational institutions. International students further support under-enrolled 
programs and disciplines, primarily STEM. In 2015, the U.S. Department of Education announced a national initiative to increase enrollment in these fields, a goal that has been sustained by a high concentration of international students in STEM disciplines (U.S. Department of Education, 2015).

However, COVID-19 led to many uncertainties regarding the continued presence and contributions of international students in the U.S. The pandemic led the U.S government to tighten immigration measures and reach several decisions that directly impacted the educational opportunities and academic progress of international students. Undoubtedly, the biggest impact was recorded in June 2020 when the U.S. Immigration and Customs Enforcement (ICE) issued a directive preventing international students enrolled in fully online coursework from remaining in the United States. Only after several universities filed a lawsuit to block the directive, the rule was rescinded and international students were granted temporary exceptions and stay (U.S. Immigration and Customs Enforcement, 2020).

Travel restrictions, which many countries imposed as a response to the pandemic, represent another factor that directly impacted the mobility of international students enrolling in U.S. institutions. In March 2020, the U.S. Department of State temporarily suspended visa services at all U.S. embassies and consulates (NAFSA, 2020a). This decision, even if warranted, directly affected all newly admitted international students by preventing them from obtaining the visas necessary to join their academic programs. Some of these students were able to defer admissions for one semester or a year; however, many students had to forego their hard-earned educational opportunities.

Among the decisions yet to be considered by the U.S. government is the recommendation to suspend OPT programs for international students (NAFSA, 2020b). This rule, if adopted, would deprive international students of critical post-graduation employment opportunities - a motivator that led many of them to choose the United States for their higher education. Even though the OPT training remains in place, national hiring freezes, especially in the higher education sector, have left many international graduates unable to find employment upon finishing their academic programs, thus having to return home.

As both higher education institutions and their students are fearfully awaiting immigration directives that may restrict them further, many of the questions that burden students remain unanswered. Even though international students make significant and long-term personal, professional, and financial commitments when they decide to study abroad, the return of that investment and the ability to see it through completion currently remain uncertain. To shed some light on these uncertainties, the purpose of this study was to 
explore the guidance and support that higher education institutions in the U.S. provided to their international students during the COVID-19 pandemic. By reviewing the websites of U.S. colleges and universities, this study investigated if and how higher education institutions responded to the ongoing and severe immigration restrictions imposed on their international students. Specifically, this study sought to answer the following research question: At U.S. colleges and universities that enroll the highest shares of non-domestic students, what guidance have offices of International Student Services (ISS) provided to support their students in times of uncertainty?

The results obtained through the analysis of the website content aimed to document if and how these institutions provided guidance and support to their international student body. Additionally, the purpose of this study was to presents the recommendations for colleges and universities that are yet to respond to their academic communities and international members seeking support, equity, and equal opportunity.

\section{LITERATURE REVIEW}

Since global competitors have been embracing more strategic and assertive approaches to the recruitment of international students, the mobility of this student population currently presents an uncertain and fluctuating phenomenon for most countries engaged in such efforts. Unfortunately, the United States emerged as one of the host countries whose international student enrollments have an unpredictable trajectory. Since the last enrollment decline that took place between 2003-2006 (1.3\% average annual decrease), the United States has achieved relatively stable growth in the number of international students it hosted over the past decade (IIE, 2019). However, the average annual increases in student enrollments have started to drop again, ranging from $10 \%$ in 2015 to only $0.05 \%$ in 2019 .

\section{International Student Mobility}

Since global competitors have been embracing more strategic and assertive approaches to the recruitment of international students, the mobility of this student population currently presents an uncertain and fluctuating phenomenon for most countries engaged in such efforts. Unfortunately, the United States emerged as one of the host countries whose international student enrollments have an unpredictable trajectory. Since the last enrollment decline that took place between 2003-2006 (1.3\% average annual decrease), the United States has achieved relatively stable growth in the number of international students it hosted over the past decade (IIE, 2019). 
However, the average annual increases in student enrollments have started to drop again, ranging from $10 \%$ in 2015 to only $0.05 \%$ in 2019 .

English-speaking countries in North America and Oceania remain among the most attractive educational destinations and they collectively host $40 \%$ of all international students around the world. The United States is commonly recognized as a leader in global student mobility, as it welcomes the highest number of international learners. However, its total share of international students among the overall student population portrays a different picture; international students in the U.S. make up only $5 \%$ of total enrollments, compared to $21 \%$ in Australia, $13 \%$ in Canada, and $12 \%$ in New Zealand (IIE, 2017).

Choudaha (2018) raised attention to three critical declines in international student enrollments in the U.S. over only two decades. Wave I, or the first significant decline, was recorded after the 9/11 attacks in 2001. Wave II was caused by the global financial crisis in 2008-2009, while Wave III was influenced by political shifts and immigration regulations implemented in 2016-2017 (Choudaga, 2018). At the same time, all three waves were accompanied by a phenomenon that is still present - increased competition from other English-speaking countries pertaining to recruitment of international students.

According to the perspectives of international students, the quality of higher education is no longer the sole decisive factor in choosing an educational destination, especially among those considering the U.S. as a host. Equally important is safety, security, and cost of educational programs (Nicholls, 2018), especially as they relate to uninterrupted academic progress and degree attainment. In many aspects, these concerns seem to be related to the rigor of U.S. immigration and visa policies that became even more stringent since the onset of the COVID-19 pandemic.

Immigration measures imposed on international students as a response to COVID-19 are not an isolated phenomenon within U.S. immigration policy. Other past U.S. government actions contributed to limiting the access of international students to higher education. For instance, in 2017, U.S. President Trump issued an executive order to suspend the entry of foreign nationals from seven countries: Iran, Iraq, Libya, Somalia, Sudan, Syria, and Yemen (Department of Homeland Security [DHS], 2018). This decision directly affected 16,216 international students enrolled in U.S. educational institutions at the time the order was activated. (IIE, 2016). The most detrimental effect of this action was reflected in the message it sent to prospective students around the world, as evidenced by the decline in the 
annual growth of international student enrollment during the following academic year.

Simultaneously, global competitors, primarily Australia, the United Kingdom, and Canada, continue to implement more deliberate recruitment efforts to increase their international student enrollment by being willing to accommodate various student needs, including immigration. As a result, Canada recorded an impressive $18 \%$ increase in its international student enrollment between 2015 and 2016, while Australia and New Zealand recorded a combined $10 \%$ rise in 2015 (IIE, 2017). These efforts occurred just as the U.S. was setting the stage for immigration measures that would result in one of the major historical declines in their global student enrollment. Contrary to U.S. practices, global competitors commonly use immigration measures to incentivize international student enrollments, such as expediting visa approvals and offering work permits during studies or after graduation (Helms, 2015; Helms et al., 2015). Canada, for instance, offers special incentives to their international students by allowing for enrollment in a Canadian university to count as extra credit in the petition for permanent residence (Canada Immigration and Citizenship, 2019).

The landscape in international student enrollment has been shifting for more than a decade. For many countries, the immigration and policy decisions made in response to the COVID-19 pandemic will define their future position as a global higher education provider. The fact that the United States has successfully come back from three waves of major enrollment declines is not necessarily a guarantee that such recovery will occur again. Even though the reputation, quality, and attractiveness of U.S. colleges and universities remain reiterated in global circles, they no longer present sufficient motivators for international students to choose the United States as their host country. Instead, the global student body is increasingly concerned with long-term prospects of their education, rather than just the quality of their college experience.

Thus, the recurring declines in international student enrollments in the United States call for a more deliberate and methodical approach to understanding not only the pre-arrival visa challenges of this student group but also their immigration experiences as they settle on U.S. campuses. Even if recruitment efforts improve and the United States restores its global competitiveness, its educational institutions are facing significant challenges in ensuring the continuous presence of international students, along with providing them with educational opportunities equal to those of domestic students. Unfortunately, immigration measures imposed since the emergence of COVID-19 further obstructed these goals, making the U.S. position on the 
global education market even more uncertain and students' academic trajectories more precarious.

\section{COVID-19 Measures}

A U.S. immigration directive was issued on July 6, 2020, stating that international students enrolled in fully online coursework in fall 2020 would not be allowed to remain in the United States. The directive further stipulated that international students enrolled in online classes would not be issued visas and would not be allowed to enter the U.S. According to the rule, enrolled students had the option to transfer to another institution that offers in-person instruction or to leave the United States. Failure to obey this directive was announced to result in immigration consequences that may include an initiation of removal proceedings (ICE, 2020).

Within days of issuing the directive, U.S. colleges, universities, and professional organizations expressed their disagreement with the rule, requesting the decision to be rescinded and international students enrolled in online courses allowed to stay in the U.S. Following a lawsuit filed by Harvard and Massachusetts Institute of Technology, the ICE directive was rescinded on August 14, 2020, and the exemptions for nonimmigrant students to enroll in fully online coursework during the pandemic were extended to the fall 2020 semester (ICE, 2020). However, the government's willingness to provide such extensions in the upcoming semesters remains unknown. This uncertainty is what makes international students concerned for their academic progress, as many of their educational institutions have already made longterm plans for online instruction due to the ongoing emergence of new COVID cases and the extensions of quarantine measures.

Before the ICE directive, the U.S. government issued several COVID-19 measures to which international students were subject. In March 2020, during the peak of the pandemic, the U.S. Department of State suspended routine immigrant and nonimmigrant visa appointments at their embassies and consulates (NAFSA, 2020a). This decision, even though warranted, prevented all newly admitted international students from obtaining student visas and arriving in the U.S. Directly affected were also all international students and scholars who were outside of the U.S. when this decision was implemented and who became unable to renew or extend their visas. Consequently, they were prevented from returning to the United States and continuing their academic careers.

Several other travel-related directives ensued, such as limiting the entry of certain international student and scholar visa categories and suspending the entry of internationals from certain countries. The most 
significant impact, however, was caused by the decision reached in June 2020, when the president issued a proclamation suspending the issuance of non-immigrant $\mathrm{H}-1 \mathrm{~B}$ visas. Historically, $\mathrm{H}-1 \mathrm{~B}$ work visas represented a critical pathway for international graduates and scholars to engage in employment in the U.S. (NAFSA, 2020a).

Among the barriers yet to be manifested is the uncertain future of Optional Practical Training (OPT), a post-graduation employment opportunity that motivates many international students to pursue their higher education in the U.S. Currently, OPT permits international students to work in the United States for 12 months upon completing an academic program or for 24 months in the case of STEM graduates. In 2019 alone, more than 223,000 international students were participating in OPT (IIE, 2019). Even though no measures have yet been taken to limit or suspend this opportunity, many public requests have been made to restrict the OPT program. Several U.S. senators and other independent groups made public recommendations and requests to end the OPT program to promote post-pandemic economic recovery and employment opportunities for U.S. citizens (NAFSA, 2020b). At the same time, many educational institutions and professional organizations issued public statements in support of international students documenting the positive impacts of their uninterrupted presence and OPT engagement.

Even if the OPT program sustains, international graduates are facing the same challenges as any other students completing academic programs uncertain employment prospects caused by national hiring freezes. The additional burden that international students encounter is that their OPT or other employment must begin 60 days after graduation in order for them to remain in the U.S. Namely, 60 days is a pre-departure preparation and grace period that international students have to either start their OPT, change their immigration status to another category (most commonly $\mathrm{H}-1 \mathrm{~B}$ ), or leave the country (USCIS, 2020). Unfortunately, the extreme impacts of the COVID19 pandemic on the U.S. economy have led to massive hiring freezes and furloughs, impeding the employment prospects of all college graduates, including international students. Hiring freezes have been especially prominent in the higher education sector, as many colleges and universities encountered financial challenges caused by unexpected costs and revenue losses. At the same time, higher education has been a leader in international students' employments, especially for international graduate students continuing their academic careers as postdoctoral scholars, researchers, and faculty. The reliance of international graduates on the higher education sector is perhaps best reflected by the legislation stating that $\mathrm{H}-1 \mathrm{~B}$ workers 
employed at an institution of higher education are not subject to the annual cap in the number of H-1B visas awarded to foreign workers (USCIS, 2020). Still, hiring freezes in the higher education sector and the previously noted suspension of H-1B visa issuance are just some of the factors that make academic and career trajectories of international students and scholars uncertain and unpredictable.

\section{Theoretical Framework}

This study was guided by the adaptive leadership framework (Heifetz, 1994; Heifetz et al., 2009). In its essence, adaptive leadership denotes individual and collective adaptations to changing and challenging environments. Specifically, adaptive leadership is "the practice of mobilizing people to tackle tough challenges and thrive" (Heifetz et al., 2009, p. 2). Practicing adaptive leadership means assisting others with the discomfort and distress they are experiencing by demonstrating compassion, while leading them through the change (Heifetz et al., 2009). This study examined if and how higher education institutions in the U.S., specifically their offices of International Student Services (ISS), utilized the adaptive leadership framework to guide their international students in the time of distress and uncertainties caused by the tightened immigration measures.

As already discussed, the recently imposed immigration restrictions and higher education reaction will affect not only international students in the U.S. will also likely shape the U.S. position in the global higher education market. Thus, applying the adaptive leadership framework in these contexts allowed for the exploration of higher education adaptation within changing environments and an expected decline in international student enrollments. Specifically, the adaptive leadership framework allowed the researcher to investigate (a) if International Student Services implemented adaptions required of them and (b) how effectively they engaged in preparing their international students to deal with the current obstacles.

\section{RESEARCH METHOD}

This research was designed as a qualitative document analysis study with a document defined as any text "that can be published or unpublished, written, oral and virtual and may reside in either the public, private or virtual domains" (Fitzgerald, 2007, p. 281). Document analysis, in particular, denotes a systematic process of reviewing and evaluating documents "in order to elicit meaning, gain understanding, and develop empirical knowledge" (Bowen, 2009, p. 27). This definition was further advanced by Tight (2019) who noted that such an analysis also includes investigating the 
purposes and context of document creation, as well as a document's ongoing use and relation to other related documents.

The document analysis research design was deemed as the most appropriate for this study because its purpose was to systematically analyze the available content by identifying common themes and extracting significant meanings (Roller \& Lavrakas, 2015). Specifically, the goal behind this design was to identify patterns, themes, and categories from the reviewed International Student Services websites that would best reflect the phenomenon examined in the research question.

\section{Data Collection}

The data for this study were collected from the websites of International Student Services (ISS) at U.S. colleges and universities that enrolled the highest share of international students in the academic year 20182019. The list of institutions was obtained from the Open Door report published annually by the Institute of International Education (IIE, 2019). The report included top 40 doctoral degree-granting universities, top 40 master's colleges and universities, top 40 baccalaureate colleges, top 40 associate's colleges, and top 40 special focus institutions enrolling international students. Together, these 200 institutions enrolled 519,046 or more than half of all international students present in the United States in 2018-2019. The researcher compiled the list of all 200 institutions and removed duplicate entries, which resulted in the final sample of 160 colleges and universities.

Once the institutions were identified, the researcher reviewed the websites of their offices of International Student Services (ISS) and examined their content. In doing so, the researcher deductively coded the website content by looking for any COVID-related announcements, reactions, or guidance that these offices provided to their international students since the pandemic outbreak in March 2020.

\section{Data Analysis}

In analyzing the website content, the researcher followed the threestage approach recommended by Roller (2019). The first stage included developing an accurate but flexible codebook that would ensure a consistent coding process. In this stage, the researcher developed an Excel spreadsheet with predefined codes that were systematically applied when reviewing each website. These codes included "Yes" or "No" codebook entries regarding the presence of items addressing COVID-response on ISS websites. The second data analysis stage involved collecting the content from ISS websites that 
provided COVID-19 response content to their international students. Specifically, this step included carefully reviewing the available content to develop structural codes or content-based words and phrases that would best illustrate that content. The third, and final stage included organizing the collected data by groups of codes and creating meaningful code clusters. These clusters are reported in the findings section as themes.

\section{Trustworthiness}

The advantage of document analysis research over other qualitative traditions is the absence of a researcher-participant relationship. Being distanced from the research participants and working with the content only, the potential bias of the researcher-participant relationship and the researcher's impact on participants do not represent a concern (Roller, 2019). At the same time, this research design poses an increased risk of researcheras-instrument bias as the researcher is independently creating and selecting the codes from the available content.

To increase the trustworthiness of the findings, the research implemented investigator triangulation (Roller, 2019) or intercoder reliability (Campbell et al., 2013). This approach involved comparing the codes that were independently developed by two different researchers. The codes and themes reported in the findings were independently developed by the principal investigator and a graduate research assistant. Then, both codebooks were reviewed and compared to solidify the interpretation of the data and increase the credibility of the findings. Both researchers offered feedback to one another as they developed the drafts of their findings and provided databased evidence (e.g. website links and content) to support their analysis. The final results reported in this study were produced when the researchers addressed all inconsistencies in their coding and reconciled these differences through collaborative analysis.

\section{RESULTS}

The review of International Student Services websites from 160 institutions revealed the following findings regarding their responses and guidance provided to international students during the COVID-19 pandemic. As illustrated in Table 1, 119 of 160 institutions had COVID-related content and updates on their ISS websites. Still, $26 \%$ of colleges and universities enrolling the highest share of international students had no COVID-related content on the websites of their International Student Services. 


\section{Table 1:}

Institutional Responses $(N=160)$

\begin{tabular}{lcc} 
COVID-related content & $\mathrm{n}$ & $\%$ \\
\hline Yes & 119 & $74 \%$ \\
No & 41 & $26 \%$ \\
\hline
\end{tabular}

It is particularly interesting to note that some of the ISS websites that had no COVID-related updates for their international students actively advertised serving and supporting this student group. Similarly, several ISS websites without any COVID-related updates contained a list of frequently asked questions for their international students, but none of these questions had any mention of COVID or immigration measures imposed during the pandemic.

Table 2:

Website Content Themes

\begin{tabular}{ll}
\hline Overarching Theme & Sub-themes \\
\hline \multirow{3}{*}{ Immigration } & I-20 documents \\
& Immigration status \\
& OPT program \\
& Visa and government services \\
\hline \multirow{3}{*}{ Employment } & Hiring freezes \\
& Post-graduation employment \\
& Remote employment \\
\hline & Admissions and transfers \\
& Academic programming \\
& Course modalities \\
Academics & Leave of absence \\
& Research \\
& Transferring in/out \\
& Travel restrictions \\
& Incoming/graduating student travel \\
\hline \multirow{2}{*}{ Travel } & Bias, discrimination, and safety \\
& Counseling and psychological support \\
& Finances \\
Student Support & Healthcare \\
& ISS operations
\end{tabular}




\section{Website Content Themes}

The thematic analysis of the content from the websites of 119 ISSs that provided COVID-19 response and guidance to their international students revealed the following five themes or code clusters: (a) Immigration, (b) Employment, (c) Academics, (d) Travel, and (e) Student Support. Table 2 illustrates sub-categories within each theme or sub-content that different institutions prioritized on their websites. Each theme and corresponding subthemes are further discussed in this section.

\section{Immigration}

The website content pertaining to immigration issues mostly focused on frequently asked questions about the I-20 document (a legal document issued by the U.S. government to international students certifying that they have been admitted to a full-time study program). This content included responses to questions about issuing I-20 documents to newly admitted students and extending I-20s for current students. The next sub-theme consisted of frequently asked questions about maintaining an international student status during the COVID pandemic. With that regard, ISSs guided students on how to maintain their student status by enrolling in a required number of courses, how to update their immigration paperwork (while inside or outside of the U.S.), and how to handle their visa expirations and extensions. Much attention has also been devoted to questions about the 5month rule (a policy stating that international students in the U.S. who are away from classes for 5 months may lose their immigration status). A separate sub-category within this theme consisted of regular ISS updates about the Student and Exchange Visitor Information System (SEVIS).

\section{Employment}

This category primarily encompassed the list of frequently asked questions related to international student remote work during the pandemic. In that regard, ISSs offered directions for students working remotely, both to those employed part-time during their studies and those participating in Optional Practical Training (OPT). Closely related to this content was guidance regarding non-traditional employment offers caused by the pandemic, such as limited hours of employment, volunteer or unpaid work, remote internships, and similar. The majority of institutions also addressed the 90-day employment rule according to which international students not seeking or securing employment may stay up to 90 dates in the U.S. upon graduation. Some ISSs listed the information about the impact of national hiring freezes on international students' ability to secure employment, while 
others handled the questions of students who were able to secure jobs but could not obtain social security numbers due to the closure of government offices.

\section{Academics}

ISS website content from this category mainly pertained to the questions related to different course modalities these institutions transitioned into during the pandemic, as well as the potential impact of different instructional formats on students' immigration status. On that note, ISSs published comprehensive guidance about course formats in which international students may enroll while maintaining their immigration status. Unsurprisingly, the bulk of the information offered was related to the academic restrictions imposed on international students by the recent ICE directive.

Students transferring in or out of an institution were given additional support, mainly concerning course modalities offered and transfer requirements. Several institutions published further guidance to their newly admitted students who were still in their home countries and who planned to defer admission due to the inability to schedule a visa appointment or to travel. Similarly, a number of ISS offices compiled a list of frequently asked questions for students planning to take a leave of absence. Several colleges and universities dedicated particular efforts to their international students still present on campuses and in residential housing. Such content mainly addressed the issues of academic and campus programming available to students during campus closures. Lastly, significant attention was dedicated to developing guidance for graduate students engaged in research, specifically regarding their inability to continue or conduct research or secure research grants and funds.

\section{Travel}

The category of travel was quite straightforward and contained consistent content among different websites. Much of the information was presented in the form of regular travel restriction updates from the Department of State, along with clarifying their potential impact on international students. The second sub-theme consisted of the most common questions from either incoming students or recent graduates, both of whom were facing mobility challenges caused by travel restrictions. ISSs also informed their students about alternative means to obtain travel signatures (required of all international students entering the U.S.). Lastly, a few ISSs provided written letter templates aimed to serve as supporting documentation 
for incoming students concerned that they would not be permitted to board their flights or enter the United States.

\section{Student Support}

The final theme comprised various frequently asked questions and updates that could not be categorized within any of the previously discussed themes. The main focal point of this content were questions related to health care, mainly health insurance coverage for COVID testing and treatment and health insurance requirements for international students residing outside of the United States. Counseling and psychological support, along with mental health resources, represented another sub-theme. Numerous institutions connected their international students with counseling centers as a means of providing psychological assistance to students who may be experiencing mental health issues caused by isolation and disconnectedness from their families and friends. Several institutions initiated commendable efforts in addressing the issues of international student discrimination that emerged during the pandemic, including but not limited to discrimination against Asian and Chinese students. The resources of this type also encompassed guidance for reporting hate crimes and discrimination against international students and general resources for all students encountering bias.

The next group of questions involved finances and inquiries about financial resources available, refund options for students not enrolled in classes, tuition and fee costs for different course modalities, and general resources for international students experiencing financial challenges. A few institutions published guidance for students who mistakenly received a stimulus check for which they were not eligible. Lastly, much of the content within this theme discussed revised hours and operations of ISS offices, alternative formats and structures of immigration advising, and website links to external resources such as the Social Security Administration, Customs and Immigration Services, Department of Homeland Security, Customs and Border Protection, Department of State, and Center for Disease Control.

\section{Official Statements}

The last group of findings obtained from ISS websites revealed that only 27 institutions or $17 \%$ of sampled colleges and universities issued an official statement in support of their international students during the COVID pandemic. Among those that made such an initiative, official statements were released by several different parties. Table 3 presents the issuing bodies among the 27 institutions that made public statements to and regarding their international students. 
Table 3:

Official Statements Issued $(N=27)$

\begin{tabular}{ll}
\hline Issuing Body & $\mathrm{n}$ \\
\hline President & 17 \\
Institution & 5 \\
Dean & 2 \\
Chancellor & 1 \\
Provost & 1 \\
Vice Provost & 1 \\
\hline
\end{tabular}

The review of the focus and content of issued statements revealed further differences among institutions. As presented in Table 4, 18 or $67 \%$ of the issued statements addressed the ICE directive preventing international students enrolled in online coursework from staying in the U.S, as well as the ICE decision to rescind the rule shortly after its implementation. The next group of statements ( 8 or 30\%) included messages of support to international students in the light of COVID-19 and tightened immigration measures. Lastly, only one statement or $4 \%$ of the content focused specifically on providing public expression of support for Chinese nationals at the institution - students, faculty, and researchers.

\section{Table 4:}

The Focus of Official Statements $(N=27)$

\begin{tabular}{ll}
\hline Statement Focus & $\mathrm{n}$ \\
\hline Reaction to ICE rule & 18 \\
Statement of support for international students & 8 \\
Statement of support for Chinese nationals & 1 \\
\hline
\end{tabular}

The first group of official statements pertaining to the ICE directive mainly expressed strong disagreement with and opposition to the ICE rule. Words of criticism, disapproval, and condemnation of the directive were the prevalent theme among the statements of this type. The second theme that emerged from these announcements were public words of celebration and congratulations issued after the directive was rescinded. Such proclamations offered reassurance for international students while praising and applauding 
the actions of higher education institutions that led to the rescinding of the directive.

The second category of statements comprised all public announcements that acknowledged the challenges that international students in the U.S. have encountered during the pandemic and offered support to these students. The majority of statements recognized the difficult circumstances that many international students encountered and expressed public promise to support their international student body in navigating these circumstances. Some institutions dedicated particular focus to expressing the appreciation for international student presence on their campuses and acknowledging the value of such presence. Others reemphasized their commitment to diversity, multiculturalism, and global engagement. Several announcements publicly condemned recent immigration and other policies that are particularly disadvantageous for international students, describing them as cruel and xenophobic.

Lastly, only one official statement particularly focused on expressing public support for Chinese students, scholars, and faculty. This message reflected on the government proclamations restricting entry for certain Chinese students and researchers and the proposed federal legislation aimed to prohibit Chinese nationals from receiving student visas in STEM fields. The institution acknowledged the value of Chinese students and scholars to their academic community and raised a concern about the arbitrary nature of these restrictions.

\section{LIMITATIONS}

The purpose of this study was to examine the response and guidance that offices of International Student Services at U.S. colleges and universities provided to their students in the time of the COVID-19 pandemic. The review of ISS websites among 160 institutions enrolling the highest share of international students revealed that even though the majority of websites (74\%) provided such guidance, the remaining $26 \%$ did not include any such content. The main themes identified from ISS website content included academics, immigration, employment, and travel guidance offered to international students. The results of this study also revealed that only 27 or $17 \%$ of the reviewed institutions issued official statements to and in support of their international students during the COVID pandemic.

Before discussing the implications of these findings, it is important to acknowledge their limitations. First, content analysts engage in the interpretation of the data only after the data have been generated. Consequently, they have to cope with the content represented in a variety of 
formats, patterns, and structures, which may cause difficulties in finding what they are looking for (Krippendorff, 2004). The researcher in this study invested significant time and effort in reviewing the content of ISS websites and searching for the information investigated. At the same time, however, this information may have been present but housed under a different webpage, thus resulting in such content to be reported in this study as nonexisting. Additionally, the content investigated in this research may have been shared with international students at these institutions via internal communication channels, such as emails, listservs, Learning Management Systems, or other platforms. The second limitation is reflected in the fact that the two major constructs examined in this study - the COVID outbreak and immigration measures - took place in March and June 2020 respectively, while the data for this study were collected in September 2020. Thus, it may be possible that the reviewed websites initially included such content but that it is no longer present.

\section{DISCUSSION}

Despite these limitations, the findings of this research yield valuable and credible insights. The advantage of document analysis over other qualitative approaches is that it can cope with large volumes of data. The ability of document analysis to investigate large volumes of text found a particular application in this study by allowing the researcher to generate findings from the review of 160 websites of the institutions that enroll more than one-half of all international students in the United States. Even though this study did not offer insights into the practices of all higher education institutions, the purposeful sample of institutions that enroll the highest share of international students allowed the researcher to draw conclusions about the COVID-related guidance and support provided to the majority of international students in the U.S.

It is critical that academic institutions and their International Student Services offices provide detailed academic guidance to all international students as their immigration status is directly dependent on the number and the format of courses they take. Further, international students are in desperate need of timely immigration guidance from their institutions in times when immigration restrictions are being continuously revised by the government. This support must not only include regular immigration updates but also active advocacy for international students' rights to continue their education and maintain their uninterrupted presence in the U.S.

In that regard, this study concludes that the majority of the sampled U.S. colleges and universities included publicly available information about 
the ways in which they supported their international students. It is also probable that other institutions provided support in different ways, such as emailing students or virtually advising them. For only $17 \%$ of the sampled colleges and universities, institutional leadership issued official statements through their ISS websites in support of their international students. Similarly, it is possible that others have implemented such actions through non-public and internal communication channels. Either way, during the global crisis of unprecedented scale, immediate, proactive, and strategic support to all students disproportionally affected by the pandemic, including international, is of the utmost importance.

As noted in the introductory section of this study, the United States has already struggled with maintaining its leading role in international student enrollments over the past decade (IIE, 2019). Unfortunately, the results from recent surveys on prospective students' intent to study in the U.S. indicate that these numbers will decrease further (IIE, 2020a). These predictions have already been confirmed by the most recent data revealing that the total number of international students at higher education institutions in the United States and studying online outside the United States decreased by $16 \%$ in Fall 2020 compared to the previous academic year (IIE, 2020b). This grim finding advances Choudaha's (2018) theory of recurring waves in international student enrollments by showing that enrollment declines are not a phenomenon of the past. It is alarming that the current, fourth wave appears to be the most drastic of them all.

Despite the admirable efforts made by many institutions from the sample, the findings of this study still indicate that the leaders from 133 institutions and 41 ISS offices did not publicly support or reassure their international students through their websites in the time of global crisis (but it is possible that they had done so through either internal channels or other public venues).These results are particularly critical when compared to the recent surveys of U.S. colleges and universities regarding how they supported international students during the pandemic. As many as $97 \%$ of respondent institutions stated they have been providing continuous support to their international students (IIE, 2020b), while 85\% reported posting updated COVID information on their websites (IIE, 2020a). As can be seen, the analysis of institutional website content revealed less favorable information. In times of uncertainty, it is critical that institutions publicly share their COVID response plans with not only currently enrolled but also prospective international students many of whom still struggle to make informed decisions about their future academic plans. 
Providing effective student support in a time of crisis is even more critical knowing that safety, security, and continuous educational access are emerging as critical factors in international student selection of a particular host destination (Nicholls, 2018). Therefore, the superb quality of education, including remote and online education highlighted by many U.S. colleges and universities, is no longer a sufficient motivator for the global student body. In that regard, the results of this research revealed that even though the majority of reviewed institutions were resolved to an adaptive leadership framework (Heifetz, 1994; Heifetz et al., 2009), they applied this framework to different extents. Namely, $74 \%$ of the institutions provided COVID-19 related content on their ISS websites which can be perceived as adaptive leadership in terms of "the practice of mobilizing people to tackle tough challenges and thrive" (Heifetz et al., 2009, p. 2). However, only $10 \%$ of institutional leaders showed public compassion to their international student body while leading them through the change. In other words, even though the majority of ISS implemented immigration adaptations required of them, very few demonstrated the traits of adaptive leadership by expressing public concern with how students adjusted to new circumstances and providing them with a supportive environment.

\section{IMPLICATION}

This study produced important implications for all higher education institutions and for ISS offices that are yet to provide their international communities with guidance and support through their websites. U.S. colleges and universities can use the findings of this study as a starting point for developing their COVID or other emergency response content for international students and for issuing official statements in support of their global student body. Several specific recommendations stem from this study.

Given the direct relationship between international students' opportunity to secure employment upon graduation and their ability to stay in the U.S., additional advice and counsel is necessary for this domain. With the uncertain future of Optional Practical Training and widespread national hiring freezes, colleges and universities must help their international students understand their employment options and make informed, rather than haphazard decisions. Next, due to the rapidly changing travel restrictions, international students need to be presented with the mobility options for their future semesters. Consequently, institutions must provide detailed guidelines for all categories of international students affected by travel restrictions actively enrolled students who are currently in the U.S., actively enrolled 
students who are currently outside of the U.S., and incoming or prospective students.

Additionally, the implications of these findings extend beyond ISS offices and apply to institutions and wider communities. Even though diversity and internationalization are frequently featured on institutional websites and used as a popular marketing tool, the results of this research revealed a different picture regarding the actual commitments to these constructs. Therefore, institutions can use the obtained results as a tool to demonstrate the dedication to their institutional values, missions, and visions. With that respect, this study serves as an important and comprehensive research record of what diversity and internationalization mean for higher education institutions in the COVID-19 environment.

This study is particularly informative for institutional leadership by offering possible ways in which they can either provide the necessary support to their international students or lead their academic communities in a time of crisis. Historically, the leadership has always had a vital role in communicating the institutional stance in times of crisis. By applying the adaptive leadership framework, leaders can embrace the roles of advocates and allies for not only international but all other student groups whose education may be disproportionally affected by the pandemic.

As we brace for the next wave of declined international enrollments, along with grim future prospects in this domain, now is the time for college leaders to take a distinct position and directly connect their proactive support of international students with the mission, vision, and values of their institutions. Given that the sample for this study consisted of colleges and universities that enroll the highest number of international students in the U.S., leading through support and compassion is critical for sustaining the global prominence of these institutions. Taking a distinct position in the current immigration debate is the first step toward wider institutional engagement and collective support to international students.

Lastly, this study offers implications for practice for all other campus stakeholders working with and supporting international students (e.g., faculty, student affairs professionals, administrators). Additionally, engaged and proactive support also means reaching out beyond institutional borders and to wider educational and social communities. Securing public support from significant allies such as professional organizations, for instance, can assist colleges and universities in reiterating the compassion and support for international students with greater trustworthiness. 


\section{CONCLUSION}

Overall, the purpose of this study was to portray the extent and scope of the support provided to international students by their academic institutions, to inform the field on best practices for supporting the global student body in times of crisis, and to identify gaps and limitations among such efforts. As a result, this study identified the commendable efforts undertaken by many colleges and universities in support of their international students. At the same time, this research elucidated the need for a more consistent, thorough, and categorical institutional support in a time of uncertainty.

The unpredictable future of the pandemic and the dismal economic outlooks make it paramount for all higher education institutions to provide timely and continuous guidance to their international students. While global student mobility will inevitably be disrupted in the months and even years to come, the students who have already invested in their international education and those who are preparing to do so deserve adequate assistance and support in accomplishing their academic plans. In that regard, this study provided a blueprint for building the necessary support systems for international students in the U.S. to benefit both parties involved - students and their educational institutions.

\section{REFERENCES}

Association of International Educators [NAFSA]. (2019). Economic value statistics. https://www.nafsa.org/policy-and-advocacy/policy-resources/nafsainternational-student-economic-value-tool-v2

Association of International Educators [NAFSA]. (2020a). COVID-19 restrictions on U.S. visas and entry. https://www.nafsa.org/regulatory-information/covid19-restrictions-us-visas-and-entry

Association of International Educators [NAFSA]. (2020b). Practical training reform. https://www.nafsa.org/professional-resources/browse-by-interest/practicaltraining-reform

Bowen, G. (2009). Document analysis as a qualitative research method. Qualitative Research Journal, 9(2), 27-40. https://doi.org/10.3316/QRJ0902027

Campbell, J. L., Quincy, C., Osserman, J., \& Pedersen, O. K. (2013). Coding in-depth semi- structured interviews: Problems of unitization and intercoder reliability and agreement. Sociological Methods \& Research, 42(3), 294320. https://doi.org/10.1177/0049124113500475

Canada Immigration and Citizenship [CIC]. (2019). Stay in Canada after graduation. http://www.cic.gc.ca/english/study/work-postgrad.asp

Choudaha, R. (2018). A third wave of international student mobility: Global competitiveness and American higher education. Research \& Occasional 
https://cshe.berkeley.edu/sites/default/files/publications/rops.cshe.8.18.cho udaha.thirdwaveinternationalstudents.4.24.2018_0.pdf

Department of Homeland Security [DHS]. (2018). Executive order 13780: Protecting the nation from foreign terrorist entry into the United States. https://www.dhs.gov/sites/default/files/publications/Executive\%20Order\% 2013780\%20Section\%2011\%20Report\%20-\%20Final.pdf

Fitzgerald, T. (2007). Documents and documentary analysis: Reading between the line. In A., Briggs and M. Coleman (Eds), Research Methods in Educational Leadership and Management (2nd ed., pp. 278-294). Sage.

Heifetz, R. (1994). Leadership without easy answers. Harvard University Press.

Heifetz, R., Grashow, A., \& Linsky, M. (2009). The theory behind the practice: A brief introduction to the adaptive leadership framework. Harvard Business Press. https://hbsp.harvard.edu/product/3241BC-PDF-ENG

Helms, R. M. (2015). Internationalizing U.S. higher education: Current policies, future directions. Report of the American Council of Education. http://www .acenet.edu/news-room/Documents/Current-Policies-FutureDirections-Part-2-US.pdf

Helms, R. M., Rumbley, L. E., Brajkovic, L., \& Mihut, G. (2015). Internationalizing higher education worldwide: National policies and programs. Report of the American Council of Education. http://www.acenet.edu/newsroom/Documents/National-Policies-and-Programs-Part-1-Global.pdf

Institute of International Education. (2016), Open doors report on international educational exchange. Retrieved from: http://www.iie.org/en/Who-WeAre/News-and-Events/Press-Center/Press-Releases/2016/2016-11-14Open-Doors-Data\#.WDXILGVlnBI

Institute of International Education. (2017). A world on the move. https://www.iie.org/Research-and-Insights/Publications/A-World-on-theMove

Institute of International Education. (2019). Open doors data. https://opendoorsdata.org

Institute of International Education. (2020a). COVID-19 snapshot survey series. https://www.iie.org/en/Connect/COVID-19/COVID-19-Snapshot-SurveySeries

Institute of International Education. (2020b). Fall 2020 international student enrollment snapshot. https://www.iie.org/Research-and-Insights/OpenDoors/Fall-International-Enrollments-Snapshot-Reports

Krippendorff, K. (2004). Content analysis: An introduction to its methodology (2nd ed.). SAGE

Nicholls, S. (2018). Influences on international student choice of study destination: Evidence from the United States. Journal of International Students, 8(2), 597-622. https://doi.org/10.5281/zenodo.1249043

Roller. M. R. (2019). A quality approach to qualitative content analysis: Similarities and differences compared to other qualitative methods. Forum: Qualitative 
https://researchdesignreview.com/2019/10/15/quality-approachqualitative-content-analysis/

Roller, M. R., \& Lavrakas, P. J. (2015). Applied qualitative research design: A total quality framework approach. The Guilford Press.

Tight, M. (2019). Documentary research in the social sciences. SAGE.

U.S. Citizenship and Immigration Services (USCIS). (2020). H-1B specialty occupations, DOD cooperative research and development project workers, and fashion models. https://www.uscis.gov/working-in-the-unitedstates/temporary-workers/h-1b-specialty-occupations-dod-cooperativeresearch-and-development-project-workers-and-fashion

U.S. Department of Education. (2015). Science, Technology, Engineering and Math: Education for global leadership. Retrieved from https://www.ed.gov/stem

U.S. Immigration and Customs Enforcement (ICE). (2020). ICE guidance on COVID. https://www.ice.gov/coronavirus

MASHA KRSMANOVIC, $\mathrm{PhD}$, is an Assistant Teaching Professor in the Higher Education and Student Affairs program at the University of Southern Mississippi. Her major research interests lie in the area of international students, student academic and social integration, first-year students, first-year experience, and college transition. Email: Masha.Krsmanovic@usm.edu 